\title{
ResearchOnline@JCU
}

This is the Accepted Version of a paper published in the journal Animal Behaviour

Pillay, Neville, and Rymer, Tasmin L. (2015) Alloparenting enhances the emotional, social and cognitive performance of female African striped mice, Rhabdomys pumilio. Animal Behaviour, 99. pp. 43-52.

http://dx.doi.org/10.1016/j.anbehav.2014.10.003 


\section{Alloparenting enhances the emotional, social and cognitive performance of female African striped mice Rhabdomys pumilio}

Neville Pillay ${ }^{\mathrm{a}^{*}}$ and Tasmin L. Rymer ${ }^{\mathrm{a}, \mathrm{b}}$

${ }^{a}$ School of Animal, Plant \& Environmental Sciences, University of the Witwatersrand, WITS 2050, Johannesburg, South Africa. Neville.Pillay@wits.ac.za

${ }^{\mathrm{b}}$ College of Marine and Environmental Sciences, James Cook University, P.O. Box 6811, Cairns, Queensland, 4870, Australia

*Corresponding author: Neville.Pillay@wits.ac.za; Tel: +27117176459; Fax: +27117176494

* This is the Accepted Version of a paper published in the journal Animal Behaviour:

Pillay, N. \& Rymer, T. L 2015. Alloparenting enhances the emotional, social and cognitive performance of female African striped mice, Rhabdomys pumilio. Animal Behaviour, 99, 43-52. 
Maternal care, either of a female's own biological offspring or fostered young, alters the behavioural, endocrine and brain functions of rodents. We asked whether female African striped mouse Rhabdomys pumilio alloparents (i.e. those assisting in raising their younger siblings) are similarly influenced. We tested if alloparental care enhances factors of ecological importance by assessing the emotional response, social competitive ability, and spatial learning and memory of age-matched, sexually mature females assigned to one of five treatments based on their housing arrangement: housed with their mothers (Alloparents), housed with their mothers, but did not raise a litter (Resident), separated from their mothers and younger siblings with a barrier (Barrier), housed alone (Alone), and primiparous breeders (Breeder). Ten females per treatment were subjected to a range of behavioural tests from 125 to 145 days of age. Breeders and Alloparents were indistinguishable in displaying greater disinhibition of novelty in open field tests, improved competitive ability during social interactions and improved spatial memory in the Barnes maze. Females that did not encounter pups (Resident, Barrier, Alone) did not show such enhanced abilities. These tests indicate that females that raise their own biological pups or help others to raise young benefit through better foraging skills and lowered anxiety in novel situations. Ultimately, alloparents derive direct benefits by improving their parental and foraging skills, in addition to indirect inclusive fitness benefits of caring for their young siblings.

Keywords: Alloparental care; Cognitive performance; Emotion; Helpers at the nest; Social competition 
For primiparous rodent mothers, parturition leads to dramatic shifts in behavioural priorities (Lambert \& Kinsley, 2012). They must provide care, including suckling, retrieving, grooming and huddling pups, essential for the development and survival of their offspring (Ziegler, Washabaugh \& Snowdon, 2004; Love et al., 2005). Moreover, mothers improve ancillary behaviours peri-partum that contribute to offspring ontogeny and maternal reproductive success. Notably, lactating female rats enhance their foraging efficiency through better spatial memory and navigational abilities (Kinsley et al., 1999), and demonstrate better exploratory and competitive behaviours (Wartella et al., 2003).

These behavioural changes are accompanied by neurobiological modifications that are maintained throughout the female's lifetime (Kinsley et al., 2008). In particular, the maternal hippocampus is sensitive to numerous hormones secreted during pregnancy (Love et al., 2005). Oestrogen, for example, stimulates increased CA1 dendritic spine density (Woolley \& McEwen, 1993) and synapses (Woolley, 1998), and increases CA1 synaptic proteins (Choi et al., 2003). Oestrogen-mediated neurological changes in the hippocampus of female Sprague-Dawley rats enhance their learning and spatial memory ability in a radial-arm maze (Kinsley et al., 1999). Furthermore, these neurological changes also decrease anxiety and increase exploration in an elevated plus maze (Neumann, 2001). The adaptive value of such neurological changes in the hippocampus is hypothesised to include improved navigation skills and concomitant resourceacquisition and homing behaviours (Kinsley et al., 1999; Lambert \& Kinsley, 2012), as well as defending unweaned young against infanticidal conspecifics (Lambert \& Kinsley, 2012).

Changes in behavioural priorities and neurobiological modifications are not confined to mothers, however. Exposure to young can also lead to changes in non-parents caring for nonrelated offspring (e.g. Kinsley et al., 1999; Lambert et al., 2005; Ruscio et al, 2008; Furuta \& 
Bridges, 2009), For example, Ruscio et al. (2008) reported that exposure to pups stimulates care behaviour (including retrieval, grooming and huddling) in non-parental prairie voles Microtus ochrogaster. Changes in other ancillary behaviours, such as enhanced spatial navigation in a dryland maze, have been reported in rats (Lambert et al., 2005). Neurobiologically, exposure to pups results in non-parents displaying site-specific changes in cell proliferation in the dentate gyrus of the hippocampus, an area important in learning and memory of spatial information (Kesner, 2007) and lower anxiety in an open field test (Lieberwirth, Liu, Jia \& Wang, 2012).

Although there is some evidence that exposure to pups alters brain regions and incidental behaviour in non-parent rodents, the findings are equivocal. For example, Furuta \& Bridges (2009) found no alterations in the hippocampus in rats. In addition, methodological inconsistencies mask a universal response. For example, females were exposed to strange pups in isolation from a group (Lambert et al., 2005), or had no prior experience with offspring and were not given the opportunity to develop care over an extended period (e.g. females were exposed to different offspring every day and only sometimes demonstrated care; Ruscio et al., 2008). In addition, the non-parents tested often represented species not known to display care for conspecific offspring under natural conditions, apart from possibly raising their offspring in a communal nest (Gilchrist, 2007).

Species with helpers at nest (i.e. alloparents) are more appropriate for studying how nonparents are influenced by caring for offspring. Alloparents are kin or non-kin individuals that naturally provide care for the younger offspring of either their biological parents (i.e. their younger siblings) or other members of the social group for extended periods (Clutton-Brock, 2002), often starting soon after weaning. Alloparental care includes all parental care type behaviours, such as feeding, offspring defence and nest maintenance, which directly or indirectly 
benefit offspring that are not immediate descendents of the alloparent (Crespi \& Yanega, 1994) and that only occur in the presence of these offspring (Woodroffe \& Vincent, 1994). The focus of alloparental care in behavioural research has mostly been on the adaptive value for alloparents and recipients of their care-giving (e.g. development of parental care skills; Salo \& French, 1989) and less attention has been paid to the ontogeny of alloparental behaviour (e.g. interactions with siblings has long-term effects on individual responsiveness to young; Saltzman et al., 2009). While it is predictable that alloparents, as for non-parents (described earlier), might also show changes in some ancillary behaviours consequent to providing care, evidence is sparse and generally limited to spatial cognition (Lambert et al., 2005), as far as we are aware.

Using our small mammal model, the African striped mouse Rhabdomys pumilio, we tested whether female alloparents show behavioural, cognitive and emotional changes when raising their younger siblings. The striped mouse is a small (40-80g) diurnal murid rodent with a widespread, although discontinuous, distribution across southern Africa (Skinner \& Chimimba, 2005). In the arid Succulent Karoo of South Africa, it forms social groups when population density is high, comprising an adult breeding male, 3-4 breeding females and their adult offspring (Schradin \& Pillay, 2004). These offspring do not reproduce in the year of their birth, but instead overwinter in the social group and help raise their younger siblings, displaying various types of alloparental behaviour, including territory defense and nest building (Schradin \& Pillay, 2004), huddling (Schradin, Schubert \& Pillay, 2006) and grooming of unweaned offspring (Rymer \& Pillay, 2014). Alloparents also alleviate the maternal workload, providing indirect benefits to breeding females (Rymer \& Pillay, 2014).

We tested whether alloparental care enhances factors of ecological importance by assessing the emotional response (challenge of open space), social competitive ability (competing with 
conspecifics for resources) and spatial learning and memory (locating food in the environment) of female alloparental striped mice. We also investigated whether direct exposure to young is required to elicit these changes or whether these can be acquired vicariously by being housed with, or in close proximity to, a mother raising offspring on her own. We hypothesized that alloparents would show behavioural and cognitive enhancements similar to parents. We made four predictions. 1) Female alloparents and breeding females would be less anxious in a novel open field environment than females without parental care experience (housed alone, housed with non-breeding mothers, housed in close proximity to breeding females but without physical access to pups). 2) Female alloparents would have a similar level of competitive ability to maternally experienced females, and both would have a greater competitive ability compared to females without parental care experience. 3) Female alloparents and breeding females would perform better in cognitive tasks than females without parental care experience. 4) Females require direct alloparenting experience (i.e. physical tactile contact) for behavioural and cognitive changes to occur.

\section{METHODS}

Subjects used in this study were the F4-5 descendants of wild-caught parents from the Succulent Karoo (Northern Cape Province, South Africa; S 29 41.56, E 18 1.60). They were housed in the Milner Park Animal Unit at the University of the Witwatersrand under partially controlled environmental conditions (14 L:10 D cycle, lights on at 0500 hours; $20-24^{\circ} \mathrm{C} ; 30-60 \%$ relative humidity). We established 30 parentally experienced breeding pairs housed in metal tanks (46 x $30 \times 32 \mathrm{~cm}$ ) with a clear PVC front and mesh lids. Tanks were furnished with a plastic nest box 
(13 x $9 \times 10 \mathrm{~cm})$, woodshavings and hay for bedding, and an assortment of enrichment devices (e.g. cardboard/plastic tubes, twigs, tissue paper). Each mouse was provided with approximately $5 \mathrm{~g}$ millet or sunflower seeds and Epol ${ }^{\mathrm{TM}}$ mouse cubes (Epol, Pretoria West, South Africa) and approximately $5 \mathrm{~g}$ fresh fruit/vegetables daily. Seed was sprinkled throughout the cage to stimulate foraging behaviour. Water was available ad libitum.

At mid-pregnancy (11-13 days, Brooks, 1982), the male was removed and housed in a separate room. Offspring were weaned at 21 days of age and one female offspring per litter was randomly selected and randomly assigned (using a random number generator) to one of three treatments ( $\mathrm{n}=10$ per treatment): (i) Alloparent - the daughter remained with her mother and, at approximately 95 days of age, helped raise her mother's second litter, as confirmed from behavioural observations of mother and female alloparents (Rymer \& Pillay, 2014); (ii) Resident - the daughter remained with her mother but neither raised a litter; and (iii) Barrier - the daughter was housed in an adjacent tank to the breeding tank housing her mother and younger siblings. The tanks were connected with a PVC pipe with a wire mesh barrier that facilitated olfactory, visual and auditory contact between striped mice in the two tanks, but prevented physical contact. The litter was born when the daughter was approximately 95 days of age. For the Alloparent and Barrier treatments, the mother was mated with her original partner when daughters were 70 days of age to age-match these females with Breeders (see below). Daughters were removed from their mothers for to prevent Alloparent females mating with the father and males being distracted by Barrier females. The males were removed following mating (about 3 days later) and the daughters re-introduced to their respective tanks. We established two additional treatments ( $\mathrm{n}=10$ per treatment) using a random selection of females: (iv) Alone - the daughter was removed from the mother at weaning and housed in isolation in a metal tank until 
used in experiments; and (v) Breeder - the daughter was paired with an unrelated male from the colony at sexual maturity ( \pm 70 days of age) and raised her first litter (primiparous) without her mate.

Starting at 125 days of age (one week after Breeders weaned their young), females from the five treatments were subjected to three experiments (below). To account for the effects of the oestrous cycle on behaviour, the oestrous stage of females was confirmed by vaginal smears taken approximately one hour before some experiments, using the pipette lavage method (Schradin \& Pillay, 2014): oestrous stage was characterised into oestrus, di-oestrus, met-oestrus and pro-oestrus, based on cell composition of the smears (Byers, Wiles, Dunn \& Taft, 2012). All experiments took place between $08 \mathrm{~h} 00$ and $12 \mathrm{~h} 00$, the peak activity period of striped mice (Rymer \& Pillay, 2011). All behaviours were scored from video recordings and the observer (NP) was blind to all treatments.

\section{Experiment 1. Emotional response in a novel environment}

The emotional response of females at 125 days of age was investigated in a novel open field arena following the methods of Reeb-Sutherland \& Tang (2011). In an unfamiliar environment, rodents often freeze (remain immobile) initially (Crawley, 2008; Post et al., 2011), then become

disinhibited, increasing locomotion and exploration of the environment (Gershenfeld et al., 1997) and finally show habituation and decreased activity (Bolivar, Caldarone, Reilly \& Flaherty, 2000). We investigated the response to novelty by exposing test females to $6 \mathrm{x} 1$ minute successive trials in an arena $(46 \times 30 \times 35 \mathrm{~cm})$ equipped with a transparent, perforated lid. Nine $10 \times 15 \mathrm{~cm}$ squares were marked on the base of the arena. This testing procedure permitted a 
better assessment of immediate response to a novel environment compared with a single trial of greater duration, in which the response to novelty dissipates after habituation (Reeb-Sutherland \& Tang, 2011). All tanks were washed with warm soapy water and alcohol and allowed to air dry before a new female was tested. Vaginal smears were taken from females before tests to ascertain oestrous state.

Test subjects were placed in an enclosed box in the middle of the arena for two minutes. The box was then lifted and the mouse was allowed to explore the arena for one minute. The mouse was returned to the enclosed box for two minutes and the procedure repeated five more times. To minimize interference, the tester remained in the same position in the room during trials. The behaviour of test subjects was video recorded using a camera mounted above the arena. From the recordings, the number of grid squares crossed was recorded. We modified the methods of ReebSutherland \& Tang (2011) by generating a disinhibition score, defined as the difference in the number of open field squares crossed between trial 3 and 1 (t3-t1) and 6 and 4 (t6-t4).

\section{Experiment 2. Social competition test}

At 132 days of age, females were tested in a social competition test. Contests test whether asymmetries between individuals determine the likelihood of one individual winning a fight (i.e. winners have greater resource holding potential, RHP; Parker, 1974). During contests, interacting individuals make tactical decisions based on both their own relative fighting abilities, usually predicted by body size differences and the value of resources being contested (Parker, 1974), although fatigue may also be a predictor of fighting ability (Arnott \& Elwood, 2009).

To investigate social competition, dyads of test females and unfamiliar stimulus females from our breeding colony were established daily for three days. Since test females were afforded 
the opportunity to explore a novel environment in Experiment 1, prior to their use in the dyads, stimulus females were also placed in an arena for 10 minutes five days before being used in dyads. As body size is a positive predictor of winning contests in striped mice (Schradin, 2004), we age- and weight-matched test and stimulus females.

Dyadic encounters were staged in metal tanks $(46.5 \times 31 \times 35 \mathrm{~cm})$ with transparent, perforated lids and transparent fronts to facilitate video recording of behaviour. Tanks were lined with a $1 \mathrm{~cm}$ deep layer of woodshavings. Each tank was divided into three equal sized (15.5 x 31 x $35 \mathrm{~cm}$ ) compartments along the longitudinal axis using opaque barriers slotted into the inside of the tank through $1 \mathrm{~cm}$ channels. This design gave both participants an opportunity to interact for the first time in a neutral space and to minimise forced territorial aggression, which is characterised by resident-intruder protocols (Reeb-Sutherland \& Tang, 2011). The test and stimulus females were randomly placed in one of the outer compartments. The females were allowed to acclimate to the tank for two minutes before the barriers were removed and the behaviour of the dyad video recorded for 11 minutes. The first minute of recording was discarded because of the disturbance of removing the barriers. A dyad was used sequentially in three tests (one per day). Vaginal smears were taken from both females in each dyad before tests on Day 1 to ascertain oestrous state. Smears were not made on Days 2 and 3 to reduce stress of handling test subjects.

On Day 1, the behaviour of the treatment female was scored using focal sampling. We scored the duration of exploratory behaviour (travelling around the tank) and the frequency of avoidance (moving away from the stimulus female), amicable behaviours (allogrooming, huddling), and aggressive encounters (biting, chasing, boxing); no damaging fights were recorded. On Day 2, 10 sunflower seeds (a favoured food source of striped mice, pers. obs.) were 
scattered in the middle compartment before the females were allowed access. We scored only the number of seeds consumed and the exploratory behaviour of the focal female because other behaviours were rare or did not occur. On Day 3, 10 sunflower seeds were again added to the middle compartment but after the focal female had consumed one sunflower seed (range $20-60$ s), the dyad was startled by loud clapping above the arena for $3 \mathrm{~s}$ by an observer. We then recorded the latency to resume seed consumption by focal females following the interruption. Elwood et al. (1998) provide a compelling argument that assessment of RHP and resource value should measure the change in motivation by providing a novel stimulus independent of the contest conditions. Several other studies showed that the duration and/or severity of the startle are negatively related to the motivation of the animal to continue its previous activity (Culshaw \& Broom, 1980; Moorehouse, Fosbrooke \& Ludlow, 1987; Jackson \& Elwood, 1990). Therefore, clapping would have provided a measure of the motivational state of animals at the start of the contest, a method to investigate whether the RHP and resource value are assessed by the dyad and how the information influences motivational state at a particular point in the contest.

\section{Experiment 3. Spatial cognition test}

When females were 145 days old, their spatial learning and memory ability was assessed in a spatial maze for eight consecutive days, followed five days later by a probe trial (after Love et al., 2005). We used a 5-hole Barnes maze (1.2 $\mathrm{m}$ in diameter and $50 \mathrm{~cm}$ high) constructed of galvanised steel. The floor of the maze was covered with a $1 \mathrm{~cm}$ thin layer of woodshavings and a transparent carrier could be placed in the middle of the maze. The five holes were equidistant apart and $2 \mathrm{~cm}$ from the bottom of the base along the walls of the maze. Each hole contained a 
short $(3 \mathrm{~cm})$ closed plastic tube placed on the outside of the maze. Sunflower seeds were used as a reward and placed in one of the tubes during experiments. Five different landmarks (e.g. rock and plastic plants of about $10 \mathrm{~cm}$ height) were placed on the surface of the maze in fixed positions to serve as visual spatial cues. There were no extra-maze cues in the room apart from a single camera lens mounted directly above the maze and a seated observer who varied her position randomly outside the maze for each female tested. Soiled bedding and faeces were removed and the woodshavings were tossed and raked between trials to redistribute the odour from earlier test subjects.

Females were tested individually. None received sunflower seeds for 10 days prior to tests in their home cages (i.e. since the end of Experiment 2) and in their home cages for the duration of Experiment 3. Females underwent training for five days (Days 1-5) in the maze, followed by three days of testing (Days 6-8). On Days 1 and 2, females were placed individually in the carrier in the middle of the maze facing north. They were released and given $5 \mathrm{~min}$ to explore and habituate to the maze. During this time, all holes were blocked with clear Perspex placed on the outside between the maze and the tubes. On Day 3, all holes were accessible and all tubes baited with two sunflower seeds. On Day 4, three randomly-selected holes were baited with two sunflower seeds and on Day 5 only one of the previously baited holes had seed. This hole became the permanently baited hole for a particular female for the test phase (below). On each training day, trials were terminated when the test females located the seeds in less than $5 \mathrm{~min}$. If a female failed to find the reward after 5 min, she was gently prodded toward the baited well. During the training phase, the sunflower seeds were placed in the front lip of the tube to encourage learning, whereas sunflower seeds were placed at the back of the tube during the test phase (below). 
On Days 6 to 8 (test phase), females were tested by changing the maze configuration daily in the following sequence: i) the maze contained landmarks for navigation as on Day 5 (landmarks); ii) the landmarks were removed (no landmarks); and iii) the maze rotated by $100^{\circ}$ so that the baited hole was moved but in same position relative to the landmarks (rotated). Each female was given three 3 min trials with 3 min inter-trial intervals and its latency to locate the baited hole was recorded. On Day 13, a single 3 min probe test was conducted to assess the memory of the previously baited hole in the same position as the test on Day 6 and including the landmarks. No bait was used during the probe test, so females had no potential olfactory perception of the seeds. We measured the latency to locate the previously baited hole, the time spent in close proximity (within $3 \mathrm{~cm}$ ) of the previously baited hole and the number of other holes visited (errors) during the probe test. We ascertained the oestrous stage of females on the day of the probe test only to reduce handling stress.

\section{Statistical analyses}

All analyses were performed using Statistica 7.1 (Statsoft Inc, www.statsoft.com). Data for all three experiments met the assumptions of homogeneity of variances (Levene's test) and normality (Shapiro-Wilks test). The model-level significance was determined at $\alpha=0.05$ and all tests were two-tailed. We used Fisher's HSD post hoc tests or orthogonal polynomial decomposition for linear and quadratic components to assess significant differences between categorical predictors or their interactions respectively (see Rymer \& Pillay, 2011).

To assess whether the random factor, litter identity (i.e. to account for genetic relatedness between breeding/non-breeding females), had an effect on measurements taken in the three experiments, we first analysed the data with variance components analysis using the Expected 
Mean Squares method. Litter identity was not a significant predictor in any of the experiments $(P$ $>0.05)$.

\section{Experiment 1. Emotional response in a novel environment}

We used a general linear model (GLM) with repeated measures multivariate design to analyse whether the disinhibition scores were influenced by treatment or trial. Treatment was the categorical predictor, trial was the repeated measures variable, disinhibition score was the dependent factor and oestrous stage was the covariate.

\section{Experiment 2. Social competition test}

Levels of aggressive and amicable behaviour were negligible, occurring in only $3 \%$ of total interactions and were therefore not considered further in the analyses. Because the behaviour of females in a dyad may be mutually dependent (i.e. females influence each other's behaviour), we first assessed the independence of the behaviour of a pair with a variance components analysis using Expected Mean Squares to establish whether pair identity (random variable) and treatment (fixed variable) influenced behaviour. Behaviour of females was not influenced by pair identity $(\mathrm{p}<0.05)$ and therefore the behaviour of females was considered to be independent.

For Day 1 of dyads, we used a GLM with multivariate design to analyse whether exploratory and avoidance behaviours were influenced by treatment and trial; oestrous stage of focal and stimulus females were covariates. We used a GLM to compare exploratory behaviour and number of seeds consumed (Day 2) and latency to resume seed consumption (Day 3) by females of the five treatments. 


\section{Experiment 3. Spatial cognition test}

For the test phase, we used a GLM with multivariate design to analyse whether the three maze configurations (landmarks, no landmarks, rotated) differed among the treatments. For the probe trial, separate GLM analyses were conducted to compare treatment differences for the latency to locate the previously baited hole, the duration of time spent within $3 \mathrm{~cm}$ of the previously baited hole and the number of errors made by females. Oestrous stage was the covariate.

\section{Ethical Note}

The research adhered to the ASAB/ABS Guidelines for the Use of Animals in Research. Animals were provided with environmental enrichment, and the welfare of the animals was monitored by daily behavioural observations and weekly weighings. The experimental procedures did not have any obvious negative effects on the welfare of the striped mice. Dyads were carefully monitored to prevent any fights; apart from chasing no physical aggression occurred. Singly kept females represented the solitary tactic observed in free-living striped mice (Schradin \& Pillay, 2014) or had olfactory, visual and auditory contact with conspecifics. At the end of the study, all experimental animals were kept as part of the breeding stock of the colony. Ethical clearance was provided by the University of the Witwatersrand (AESC 2010/55/2A, 2013/18/2A).

\section{RESULTS}

Experiment 1. Emotional response in a novel environment 
Disinhibition scores were influenced by the interaction between treatment and trial $\left(F_{4,43}=4.72\right.$, $P=0.003)$. Post hoc analyses showed that, in Period 1 (t3-t1), the Alloparent and Breeder treatments had the highest disinhibition scores and the Alone treatment had the lowest score (Fig. 1). The other treatments/trials occupied an intermediate position (Fig. 1). Interestingly, the disinhibition score of the Alone treatment in Period 2 (t6-t4) increased to similar levels of the Alloparent and Breeder treatments in Period 1, indicating an extinction of the anxiety response in this group (Fig. 1). All other treatments/trials grouped together (Fig. 1). None of the other factors predicted disinhibition scores: treatment $\left(F_{4,43}=1.20, P=0.324\right)$, trial $\left(F_{1,43}=1.27, P=0.266\right)$ and oestrous stage $\left(F_{1,43}=0.68, P=0.414\right)$.

Treatment $\left(F_{4,43}=10.78, P<0.001\right)$ and treatment $\mathrm{x}$ trial $\left(F_{12,129}=2.55, P=0.005\right)$ were significant predictors of total number of squares crossed in trials 1, 3, 4 and 6 (Table 1). A linearquadratic polynomial decomposition $(t=3.80, P<0.001)$ indicated low values for all treatments on trial 1, with the Alone treatment being the lowest (Table 1). This was followed by an increase in squares crossed gradually for the Barrier, Resident and Alone treatments initially and peaking on trial 6 (Table 1). In contrast, the Alloparent and Breeder treatments maintained a high number of squares crossed from trial 3 to 6 , being highest in the Alloparent treatment. Trial $\left(F_{3,43}=0.84\right.$, $P=0.474)$ and oestrous state $\left(F_{1,43}=1.19, P=0.281\right)$ did not affect the number of squares crossed.

\section{Experiment 2. Social competition test}

On Day 1 of dyads, treatment was a significant predictor of exploratory behaviour $\left(F_{4,42}=9.95\right.$, $P<0.001)$ but not of avoidance $\left(F_{4,42}=0.44, P=0.782\right)$. Exploratory behaviour was greatest in 
the Alloparent and Breeder treatments and lowest in the Alone treatment; the Barrier and Resident treatments occupied an intermediate position (Fig. 2). Oestrous stage of the focal female and the stimulus female did not predict exploratory $\left(F_{1,42}=0.03, P=0.853 ; F_{1,42}=0.17\right.$, $P=0.686$, respectively $)$ or avoidance $\left(F_{1,42}=0.19, P=0.664 ; F_{1,42}=0.51, P=0.479\right)$ behaviours respectively.

On Day 2 of dyads when sunflower seeds were added, the exploratory behaviour of focal females was significantly influenced by treatment $\left(F_{4,45}=5.45, P=0.001\right)$. The Breeder treatment showed the greatest duration of exploration, followed by the Alloparent and Barrier treatments, with the Resident and Alone females showing the lowest duration of exploration (Fig. 3). The number of seeds consumed did not differ between treatments $\left(F_{4,45}=1.17, P=\right.$ 0.339; Fig. 3).

On Day 3 of dyads, the latency to resume feeding following a disturbance (loud clapping) was influenced by treatment $\left(F_{4,45}=5.81, P<0.001\right)$. The Alone treatment took the longest time to resume feeding on sunflower seeds following the disturbance and the Breeder treatment were the quickest to respond (Fig. 4). All other treatments showed an intermediate response (Fig. 4).

\section{Experiment 3. Spatial cognition test}

At the end of the training phase, all females, barring one from the Alone treatment, located the maze within 5 minutes (98\% accuracy), indicating that animals had successfully learnt the task during the training phase. During the test phase, treatment $\left(F_{4,90}=12.09, P<0.001\right)$, maze configuration $\left(F_{2,90}=59.94, P<0.001\right)$ and treatment $\mathrm{x}$ maze configuration $\left(F_{8,90}=8.60, P<\right.$ 0.001) were significant predictors of the latency to locate the baited hole. Post hoc tests revealed 
that Breeder and Alloparent treatments found the hole the fastest and latency was longest in the no landmark trials. A significant linear polynomial decomposition $(t=-5.71, P<0.001)$ revealed a decrease in the latency of the Alloparent and Breeder treatments in the landmark and rotated mazes to all other treatments and maze configurations (Fig. 5). The quadratic polynomial decomposition was not significant $(t=0.12, P=0.906)$.

For the probe test, treatment influenced time spent in close proximity to the previously baited hole (duration; $F_{4,44}=9.54, P<0.001$ ) and the number of incorrect holes visited (errors; $\left.F_{4,44}=7.26, P<0.001\right)$. Post hoc tests showed that duration was greatest in the Breeder and Alloparent treatments compared to the other treatments, whereas errors made were lowest in the Alloparent and Breeder treatments, intermediate in the Barrier treatment and highest in the Alone and Resident treatments (Fig. 6). Latency to locate the previously baited hole was not influenced by treatment $\left(F_{4,44}=2.20, P=0.084\right)$ : Alone $=92.8 \pm 5.66 \mathrm{~s} ;$ Breeder $=69.0 \pm 10.64 \mathrm{~s} ;$ Barrier $=$ 93.2 $\pm 6.88 \mathrm{~s} ;$ Resident $=100.2 \pm 9.79 \mathrm{~s} ;$ Alone $=82.2 \pm 5.66 \mathrm{~s}$. Oestrous stage did not predict latency $\left(F_{1,44}=1.22, P=0.275\right)$, duration $\left(F_{1,44}=0.76, P=0.387\right)$ and errors made $\left(F_{1,44}=0.76\right.$, $P=0.388)$.

\section{DISCUSSION}

We investigated whether alloparental care enhances the emotional response, social competitive ability and spatial learning and memory of female striped mice, and whether direct exposure to young is required to elicit these modifications. In agreement with our first prediction, Alloparent females were less anxious, showing high disinhibition scores (up to 4 times higher than Barrier, Resident AND Alone females) between days 1 and 3 in novel open field environments 
(Experiment 1). Alloparents were similar to Breeders, indicating that experience of raising pups improves the rate of habituation in a novel environment, a finding consistent with those of other rodent studies in rats (Lambert et al., 2005) and voles (Kesner, 2007; Ruscio et al, 2008). That females without maternal care experience (Barrier, Resident and Alone) increased their disinhibition scores later between days 4 to 6 in the open field tests suggests firstly that these females required longer periods to habituate to the novel arena (Bolivar, Caldarone, Reilly \& Flaherty, 2000), and secondly that the plasticity in the anxiety response to novelty is sensitive to previous alloparental/maternal care, as seen in female rats (Wartella et al., 2003).

For our second prediction, we expected that experience with pups would influence the competitive ability of female striped mice. In dyadic encounters, greater exploration is a measure of dominance (Cranford \& Derting, 1983; Kinahan \& Pillay, 2008), as well as a measure of reduced anxiety (Carola, D’Olimpio, Brunamonti, Mangia \& Renzi, 2002; Prior, Schwegler, Marashi \& Sachser 2004). We also established the RHP of contestants by startling the dyad and measuring how the change in motivation affected the resumption of feeding on the highly nutritious sunflower seeds, which was a particularly important measurement because of the absence of overt aggression that could have been used to measure competitive ability. In dyadic encounters (Experiment 2), Alloparents were not as competitive as Breeders, but were more competitive than Resident and Alone females. Therefore, our data indicate that the provision of maternal and alloparental care potentially enhances RHP.

While some studies report high levels of aggression motivated by access to limiting food (Blanchard, Wall \& Blanchard, 2003; Demas, Polacek, Durazzo \& Jasnow, 2004; Karl et al., 2004), our treatments showed very little overt aggression and did not differ in the numbers of sunflower seeds consumed. These results most likely reflect the optimal conditions of captivity 
(i.e. sufficient food) which do not pose an energetic challenge for striped mice and reduce competition for a high quality resource. In contrast, free-living striped mice compete aggressively for limiting food in the harsh arid Succulent Karoo (Schradin, 2004), suggesting that Breeders and Alloparents might have a competitive advantage for exploiting transient high protein food resources, which directly affects female fitness (Schradin \& Pillay, 2006). This is reflected in the decreased latency to resume exploring and feeding by Alloparents and Breeders, following a disturbance.

In the Barnes maze (Experiment 3), Alloparent and Breeder females located a food reward faster when landmarks were available, spent more time in the vicinity of a previously baited hole, and made fewer errors during the probe trial compared to females with no experience with pups. Therefore, in support of our third prediction, experience with pups improves both short (working) and longer-term memory in striped mice. Similar improved memory has been observed in rat and mice mothers, with reports of either long-term (Lambert et al., 2005; Tomizawa et al., 2003) or both short and long-term (Gatewood et al., 2005) effects. Interestingly, treatments did not differ in their performance in the no landmark maze, indicating that striped mice become disorientated in the Barnes maze without visual cues (landmarks), as reported for rats tested in an appetitive radial arm maze (Dudchenko, Goodridge, Seiterle \& Taube, 1997) and a plus maze (Martin, Harley, Smith, Hoyles \& Hynes, 1997). However, Alloparents and Breeders retained a memory of the baited hole five days after tests in the probe tests.

The Barnes maze experiment is an appetitive task, requiring females to locate prized sunflower seeds. The enhanced cognition of Alloparents and Breeders suggests that they might be able to acquire resources faster and more efficiently. Although striped mice in the Succulent Karoo live in groups and have communal nests, they forage alone, possibly to reduce predation 
risk (Schradin \& Pillay, 2004). Females that experience raising pups, whether Breeders or Alloparents, will have a distinct advantage over females without experience, because they are more likely to remember the location of food patches and quickly exploit high quality food, thereby enhancing their fitness. Furthermore, improved foraging efficiency could reduce the time spent away from the litter and reduce energetic expenditure during the high energy phase of lactation (Love et al., 2005).

In support of our fourth prediction, exposure to visual, olfactory and auditory cues of pups was not sufficient to improve cognition and behaviour in Barrier females, indicating the importance of physical contact on behavioural and cognitive changes, as occurred in Alloparent females. While other studies have demonstrated that parenting enhances cognition and resourceacquisition skills (e.g. Kinsley et al., 1999; Lambert et al., 2005; Ruscio et al, 2008; Lieberwirth et al., 2012), none explicitly tested the significance of tactile contact. Rodents rely largely on vibrissae-based tactile discrimination when exploring novel environments, food and their offspring. Stimulation of the whiskers elicits neuronal firing in the entorhinal cortex, which further elicits localised responses in the dentate gyrus of the hippocampus (Bellistri, Aguilar, Brotons-Mas, Foffani \& Menendez de la Prida, 2013). While Ruscio et al. (2008) reported that exposure to unrelated pups can stimulate site-specific changes in cell proliferation in the hippocampal dentate gyrus, our results suggest that physical contact is explicitly effecting these changes, because Barrier females did not show the enhancements of Alloparents and instead resembled both Alone and Resident females that had no exposure to pups.

The close association (i.e. tactile contact) between alloparents and their pregnant mothers, which was absent in other treatments, might be another explanation for the increased parental responsiveness, as reported in male mice Mus musculus cohabiting with a pregnant female 
(Elwood, 1985). In our study, Barrier treatment females often showed an intermediate response between the Alloparent and Breeder females and the Alone and Barrier females, suggesting that a close association with a pregnant mother, but absence of physical contact, provides some cognitive benefits, but not to the extent of alloparental females.

Our study is not the first to show that nulliparous females show enhanced cognition (e.g. Kinsley et al., 1999; Lambert et al., 2005). However, we do demonstrate that Alloparents benefit both behaviourally and cognitively from providing care to the same extent as Breeders, which has not been documented previously. We offer four mutually non-exclusive hypotheses for the mechanisms underlying these behavioural and cognitive changes, which should be viewed as opportunities for future studies.

1) Oxytocin, a neuropeptide hormone produced in the hypothalamus predominantly (Gimpl \& Fahrenholz, 2001) and also the ventral subiculum of the hippocampus (Barberis \& Tribollet, 1996), is released from the posterior pituitary upon stimulation of tactile receptors, particularly during parturition, lactation and suckling (Gimpl \& Fahrenholz, 2001). This stimulation generates sensory impulses that are transmitted to the spinal cord and then to the secretory hypothalamic oxytocinergic neurons, which release oxytocin into the blood stream, from where it acts on the mammary glands, stimulating milk ejection (Gimpl \& Fahrenholz, 2001). Tomizawa et al. (2003) reported that oxytocin has long lasting effects on spatial memory in C57BL6 mice, through activation of the MAP kinase cascade and CREB phosphorylation. Oxytocin may be involved in the formation of spatial memory in Breeders resulting from parturition, lactation and suckling. Although Alloparents did not experience parturition and suckling, their social attachment to their mothers and siblings (Rymer \& Pillay, 2014) could also elevate oxytocin levels (Coria-Avila et al., 2014), thereby influencing spatial memory. Moreover, high oxytocin 
receptor density in the nucleus accumbens is also correlated with high alloparental care behaviour (e.g. licking and grooming pups and huddling) in prairie voles (Ross \& Young, 2006), suggesting a reinforcing relationship between social attachment-oxytocin secretion-alloparent care.

2) Oestrogen induces permanent and irreversible organizational and/or activational effects on the central nervous system (Arnold \& Breedlove, 1985). The hippocampus is particularly sensitive to high oestrogen levels, especially oestradiol (Segal \& Murphy, 2001; Pawluski \& Galea, 2007). Oestradiol increases hippocampal dendritic spine density, often occurring rapidly in association with the oestrous cycle (Woolley \& McEwen, 1992). These dendritic spines are important areas for the enhancement of synaptic networks that are involved in learning (Leuner $\&$ Shors, 2004). Short-term fluctuations in oestradiol are sufficient to increase dendritic spine density in nulliparous female rats (Kinsley et al., 2006) and hippocampal plasticity is known to regulate learning and spatial memory ability (Kinsley et al., 1999). Oestrogen improves spatial learning and memory (Daniel, Fader, Spencer \& Dohanich, 1997; Luine, Richards, Wu \& Beck, 1998; Frick, Fernandez \& Bulinski, 2002) through enhancement of the function of cholinergic neurons in the hippocampus (Rissanen, Puoliväli, van Groen \& Riekkinen, 1999) and changes in activity of cortical and basal forebrain monoaminergic and amino acid transmitters (Luine et al., 1998). In addition, oestrogen increases hippocampal synaptophysin (a calcium-binding glycoprotein found in neurotransmitter-containing presynaptic vesicles; Wiedenmann \& Franke, 1985) expression (Pozzo-Miller, Inoue \& Murphy, 1999), which is associated with improved spatial reference memory (Frick, Fernandez \& Bulinski, 2002). Oxytocin receptor binding in the medial preoptic area of the hypothalamus is also oestrogen dependent (Champagne, Diorio, Sharma \& Meaney, 2001), synergistically enhancing spatial memory, and mediating reference 
memory (Pawluski, Walker \& Galea, 2006). While the link between oestrogen and oxytocin could explain enhanced spatial cognition in Breeders AND Alloparents, oestrus stage was not a predictor of the behavioural responses in experiments. However, oestrogen-mediated organisational changes in the brains of Alloparent and Breeder females is likely to have occurred earlier during pup rearing, since they would have displayed several oestrus cycles (Pillay unpublished).

3) The hormones associated with pregnancy and lactation appear to mitigate the effects of stress (Lambert et al., 2005) through down-regulation of the hypothalamic-pituitaryadrenocortical (HPA) axis (Taylor et al., 2000). For example, lactating rats were less behaviourally responsive to an auditory stress, and also showed no significant activation of the HPA axis (Windle et al., 1997), and Lambert et al. (2005) proposed that enhanced behavioural performance of rats in spatial cognitive tasks could be a result of modification of HPA axis activation. Lactating rats increase exploration in the elevated plus maze (Neumann, 2001), and both pregnant and maternally-experienced females (i.e. females that previously raised a litter) increase rates of exploration in an open field (Wartella et al., 2003). Elevated levels of corticosterone in response to stress results in atrophied dendrites of hippocampal CA3 pyramidal neurons (Watanabe, Gould \& McEwen, 1992; Lambert et al., 1998) and inhibits the hippocampal dentate gyrus (Pawluski \& Galea, 2007). Since chronic stress (and hence increased corticosterone) is known to impair spatial working memory (Luine, Villegas, Martinez \& McEwen, 1994), down-regulation of the HPA axis could provide a cognitive benefit for animals displaying parental care, which could explain why Breeder and Alloparental females had enhanced behavioural performance and demonstrated fewer errors. Furthermore, oxytocin is released following a stress response (Neumann, Torner \& Wigger, 2000; Carter, 1998), further 
attenuating the HPA axis responsiveness (Lambert et al., 2005), which could explain the responses of the Breeders and possibly Alloparents.

4) Care-giving behaviour is complex and polygenic (Agrawal, Brodie \& Brown, 2001), and there are indications that the expression of both maternal care and alloparental care might be governed by the same underlying genetic mechanisms (Linksvayer \& Wade, 2005). For example, in the eusocial wasp Polistes metricus, gene expression, particularly insulin-related genes regulating female provisioning (alloparental care) and those displaying maternal are similar (Toth et al., 2007), suggesting that similar mechanistic pathways regulate alloparental and maternal care.

Our study is the first to show that contact with pups enhances cognitive and behavioural performance of nulliparous alloparent females. Tactile cues, possibly in combination with oestrogen spikes during the oestrous cycle and the influence of oxytocin, mediate these enhancements. The focus of many alloparental care studies in behavioural research has been on the adaptive value for alloparents and recipients of their care-giving, with little or no attention being paid to the cognitive enhancements and resource acquisition skills that alloparents might accrue. Such benefits might improve their ability to navigate, compete with conspecifics and locate resources, enhancing their fitness and that of any non-biological young they raise. Moreover, these benefits accrued by alloparents that become breeders later might lead to better provisioning of their own offspring (Lambert et al., 2005) and possibly epigenetic enhancement of learning, memory and resource acquisition in their offspring (Tang, Akers, Reeb, Romeo \& McEwen, 2006).

\section{ACKNOWLEDGEMENTS}


We are very grateful for the help provided by research assistants. Funding was provided by the National Research Foundation, South Africa (Grant number: 87769) and the University of the Witwatersrand. We thank Robert Elwood and two reviewers for their helpful suggestions for improving our manuscript.

\section{REFERENCES}

Agrawal, A. F., Brodie III, E. D. \& Brown, J. (2001). Parent-offspring coadaptation and the dual genetic control of maternal care. Science, 292, 1710-1712. http://dx.doi.org/10.1126/science.1059910.

Arnold, A. P., \& Breedlove, S. M. (1985). Organizational and activational effects of sex steroids on brain and behavior: a reanalysis. Hormones \& Behavior, 19, 469-498. http://dx.doi.org/10.1016/0018-506X(85)90042-X.

Arnott, G., \& Elwood, R. (2009). Assessment of fighting ability in animal contests. Animal Behaviour, 77, 991-1004. http://dx.doi.org/10.1016/j.anbehav.2009.02.010.

Barberis, C., \& Tribollet, E. (1996). Vasopressin and oxytocin receptors in the central nervous system. Critical Reviews in Neurobiology, 10, 119-154. http://dx.doi.org/10.1615/CritRevNeurobiol.v10.i1.60.

Bellistri, E., Aguilar, J., Brotons-Mas, J. R., Foffani, G., \& Menendez de la Prida, L. (2013). Basic properties of somatosensory-evoked responses in the dorsal hippocampus of the rat. Journal of Physiology, 591, 2667-2686. http://dx.doi.org/10.1113/jphysiol.2013.251892.

Blanchard, R. J., Wall, P. W., \& Blanchard, D. C. (2003). Problems in the study of rodent aggression. Hormones \& Behavior. 44, 161-170. http://dx.doi.org/10.1016/S0018$\underline{506 X(03) 00127-2 .}$ 
Bolivar, V. J., Caldarone, B. J., Reilly, A. A., \& Flaherty, L. (2000). Habituation of activity in an open field: a survey of inbred strains and $\mathrm{F}_{1}$ hybrids. Behavior Genetics, 30, 285-293. http://dx.doi.org/10.1023/A:1026545316455.

Brooks, P. M. (1982). Aspects of the reproduction, growth and development of the four-striped mouse, Rhabdomys pumilio (Sparrman 1784). Mammalia, 46, 53-64. http://dx.doi.org/10.1515/mamm.1982.46.1.53.

Byers, S. L., Wiles, M. V., Dunn, S. L., \& Taft, R. A. (2012). Mouse estrous cycle identification tool and images. PLoS One, 7, e35538. http://dx.doi.org/10.1371/journal.pone.0035538.

Carola, V., D’Olimpio, F., Brunamonti, E., Mangia, F., \& Renzi, P. (2002). Evaluation of the elevated plus-maze and open-field tests for the assessment of anxiety-related behaviour in inbred mice. Behavioural Brain Research, 134, 49-57. http://dx.doi.org/10.1016/S0166$\underline{4328(01) 00452-1 .}$

Carter, C. S. (1998). Neuroendocrine perspectives on social attachment and love. Psychoneuroendocrinology, 23, 779-818. http://dx.doi.org/10.1016/S0306-4530(98)00055-9.

Champagne, F., Diorio, J., Sharma, S., \& Meaney, M. J. (2001). Variations in maternal care in the rat are associated with differences in estrogen-related changes in oxytocin receptor levels. Proceedings of the National Academy of Sciences USA, 98, 12736-12741. http://dx.doi.org/10.1073/pnas.221224598.

Choi, J. M., Romeo, R. D., Brake, W. G., Bethea, C. L., Rosenwaks, Z., \& McEwen, B. S. (2003). Estradiol increases pre- and post-synaptic proteins in the CA1 region of the hippocampus in female rhesus macaques (Macaca mulatta). Endocrinology, 144, 4734-4738. http://dx.doi.org/10.1210/en.2003-0216.

Clutton-Brock, T. H. (2002). Breeding together: Kin selection and mutualism in cooperative 
vertebrates. Science, 296, 69-72. http://dx.doi.org/10.1126/science.296.5565.69.

Coria-Avila, G. A., Manzoa, J., Garcia, L. I., Carrillo, P., Miquel, M., \& Pfaus, J. G. (2014). Neurobiology of social attachments. Neuroscience Biobehavioral Reviews, 43, 173-182. http://dx.doi.org/10.1016/j.neubiorev.2014.04.004.

Cranford, J. A., \& Derting, T. L. (1983). Intra and interspecific behavior of Microtus pennsylvanicus and Microtus pinetorum. Behavioral Ecology and Sociobiology, 13, 7-11. http://dx.doi.org/10.1007/BF00295070.

Crawley, J. N. (2008). Behavioral phenotyping strategies for mutant mice. Neuron, 57, 809-818. http://dx.doi.org/10.1016/j.neuron.2008.03.001.

Crespi, B. J., \& Yanega, D. (1994). The definition of eusociality. Behavioral Ecology, 6, 109115. http://dx.doi.org/10.1093/beheco/6.1.109.

Culshaw, A. D., \& Broom, D. M. (1980). The imminence of behavioural change and startle responses of chicks. Behaviour, 73, 64-76. http://www.jstor.org/stable/4534032.

Daniel, J. M., Fader, A. J., Spencer, A. L., \& Dohanich, G. P. (1997). Estrogen enhances performance of female rats during acquisition of a radial arm maze. Hormones and Behavior, 32, 217-225. http://dx.doi.org/10.1006/hbeh.1997.1433.

Demas, G. E., Polacek, K. M., Durazzo, A., \& Jasnow, A. M. (2004). Adrenal hormones mediate melatonin-induced increases in aggression in male Siberian hamsters (Phodopus sungorus). Hormones \& Behavior, 46, 582-591. http://dx.doi.org/10.1016/j.yhbeh.2004.07.001.

Dudchenko, P. A., Goodridge, J. P., Seiterle, D. A., \& Taube, J. S. (1997). Effects of repeated disorientation on the acquisition of spatial tasks in rats: dissociation between the appetitive radial arm maze and aversive water maze. Journal of Experimental Psychology, 23, 194-210. http://dx.doi.org/10.1037/0097-7403.23.2.194. 
Elwood, R. W. (1985). Inhibition of infanticide and onset of paternal care in male mice (Mus musculus). Journal of Comparative Psychology, 99, 457-467. http://dx.doi.org/10.1037/07357036.99.4.457.

Elwood, R. W., Wood, K. E., Gallagher, M. B., \& Dick, J. T. A. (1998). Probing motivational state during agonistic encounters in animals. Nature, 393, 66-68. http://dx.doi.org/10.1038/29980.

Frick, K. M., Fernandez, S. M., \& Bulinski, S. C. (2002). Estrogen replacement improves spatial reference memory and increases hippocampal synaptophysin in aged female mice. Neuroscience, 115, 547-558. http://dx.doi.org/10.1016/S0306-4522(02)00377-9.

Furuta, M., \& Bridges, R. S. (2009). Effects of maternal behavior induction and pup exposure on neurogenesis in adult, virgin female rats. Brain Research Bulletin, 80, 408-413. http://dx.doi.org/10.1016/j.brainresbull.2009.08.011.

Gatewood, J. D., Morgan, M. D., Eaton, M., McNamara, I. M., Stevens, L. F., Macbeth, A. H., Meyer, E. A. A., Lomas, L. M., Kozub, F. J., Lambert, K. G., \& Kinsley, C. H. (2005). Motherhood mitigates aging-related decrements in learning and memory and positively affects brain aging in the rat. Brain Research Bulletin, 66, 91-98. http://dx.doi.org/10.1016/j.brainresbull.2005.03.016.

Gilchrist, J. S. (2007) Cooperative behaviour in cooperative breeders: costs, benefits, and communal breeding. Behavioural Processes, 76, 100-105. http://dx.doi.org/10.1016/j.beproc.2006.12.013.

Gimpl, G., \& Fahrenholz, F. (2001). The oxytocin receptor system: structure, function, and regulation. Physiological Reviews, 81, 629-683.

http://physrev.physiology.org/content/81/2/629.full.pdf. 
Hames, R., \& Draper, P. (2004). Womens' work, child care, and helpers-at-the-nest in a huntergatherer society. Human Nature, 15, 319-341. http://dx.doi.org/10.1007/s12110-004-1012-x.

Jackson, N. W., \& Elwood, R. W. (1990). Interrupting an assessment process to probe changes in motivational state. Animal Behaviour, 39, 1068-1077. http://dx.doi.org/10.1016/S00033472(05)80779-1.

Karl, T., Lin, S., Schwarzer, C., Sainsbury, A., Couzens, M., Wittmann, W., Boey, D., von Hörsten, S., \& Herzog, H. (2004). Y1 receptors regulate aggressive behavior by modulating serotonin pathways. Proceedings of the National Academy of Science USA, 101, 1274212747. http://dx.doi.org/10.1073/pnas.0404085101.

Kesner, R. P. (2007). A behavioral analysis of dentate gyrus function. Progress in Brain Research, 163, 567-576. http://dx.doi.org/10.1016/S0079-6123(07)63030-1.

Kinahan, A. A., \& Pillay, N. (2008). Dominance status influences female reproductive strategy in a territorial African rodent Rhabdomys pumilio. Behavioral Ecology and Sociobiology, 62, 579-587. http://dx.doi.org/10.1007/s00265-007-0482-3.

Kinsley, C. H., Bardi, M., Karelina, K., Rima, B., Christon, L., Friedenberg, J., \& Griffin, G. (2008). Motherhood induces and maintains behavioral and neural plasticity across the lifespan in the rat. Archives of Sexual Behavior, 37, 43-56. http://dx.doi.org/10.1007/s10508-007$\underline{9277-x}$.

Kinsley, C. H., Madonia, L., Gifford, G. W., Tureski, K., Griffin, G. R., Lowry, C., Williams, J., Collins, J., McLearie, H., \& Lambert, K. G. (1999). Motherhood improves learning and memory. Nature, 402, 137-138. http://dx.doi.org/10.1038/45957.

Kinsley, C. H., Trainer, R., Stafisso-Sandoz, G., Quadros, P., Marcus, L. K., Hearon, C., Meyer, E. A. A., Hester, N., Morgan, M., Kozub, F. J., \& Lambert, K. G. (2006). Motherhood and the 
hormones of pregnancy modify concentrations of hippocampal neuronal dendritic spines.

Hormones and Behavior, 49, 131-142. http://dx.doi.org/10.1016/j.yhbeh.2005.05.017.

Lambert, K. G., \& Kinsley, C. H. (2012). Brain and behavioral modifications that accompany the onset of motherhood. Parenting: Science and Practice, 12, 74-88. http://dx.doi.org/10.1080/15295192.2012.638868.

Lambert, K. G., Berry, A. E., Griffins, G., Amory-Meyers, E., Madonia-Lomas, L., Love, G., \& Kinsley, C. H. (2005). Pup exposure differentially enhances foraging ability in primiparous and nulliparous rats. Physiology \& Behavior, 84, 799-806.

http://dx.doi.org/10.1016/j.physbeh.2005.03.012.

Lambert, K. G., Buckelew, S. K., Staffiso-Sandoz, G., Gaffga, S., Carpenter, W., Fisher, J., \& Kinsley, C. H. (1998).. Activity-stress induces atrophy of apical dendrites of hippocampal pyramidal neurons in male rats. Physiology \& Behavior, 65, 43-49. http://dx.doi.org/10.1016/S0031-9384(98)00114-0.

Leuner, B., \& Shors, T. J. (2004). New spines, new memories. Molecular Neurobiology, 29, 117-130. http://dx.doi.org/10.1385/MN:29:2:117.

Lieberwirth, C., Liu, Y., Jia, X., \& Wang, Z. (2012). Social isolation impairs adult neurogenesis in the limbic system and alters behaviors in female prairie voles. Hormones \& Behavior, 62, 357-366. http://dx.doi.org/10.1016/j.yhbeh.2012.03.005.

Linksvayer, T. A. \& Wade, M. J. (2005). The evolutionary origin and elaboration of sociality in the aculeate hymenoptera: Maternal effects, sib-social effects, and heterochrony. The Quarterly Review of Biology, 80, 317-336.

Love, G., Torrey, N., McNamara, I., Morgan, M., Banks, M., Hester, N. W., Glasper, E. R., DeVries, A. C., Kinsley, C. H., \& Lambert, K. G. (2005). Maternal experience produces long- 
lasting behavioral modifications in the rat. Behavioral Neuroscience, 119, 1084-1096. http://dx.doi.org/10.1037/0735-7044.119.4.1084.

Luine, V., Villegas, M., Martinez, C. \& McEwen, B. S. (1994). Repeated stress causes reversible impairments of spatial memory performance. Brain Research, 639, 167-170. http://dx.doi.org/10.1016/0006-8993(94)91778-7.

Luine, V. N., Richards, S. T., Wu, V. Y., \& Beck, K. D. (1998). Estradiol enhances learning and memory in a spatial memory task and effects levels of monoamingergic neurotransmitters. Hormones and Behavior, 34, 149-162. http://dx.doi.org/10.1006/hbeh.1998.1473.

Martin, G. M., Harley, C. W., Smith, A. R., Hoyles, E. S., \& Hynes, C. A. (1997). Spatial disorientation blocks reliable goal location in a plus maze but does not prevent goal location in the Morris maze. Journal of Experimental Psychology, 23, 183-193. http://dx.doi.org/10.1037/0097-7403.23.2.183.

Moorehouse, J. E., Fosbrooke, I. H. M., \& Ludlow, A. R. (1987). Stopping a walking locust with sound: an analysis of variation in behavioural threshold. Experimental Biology, 46, 193-201. http://europepmc.org/abstract/MED/3582590.

Neumann, I.D. (2001). Alterations in behavioural and neuroendocrine stress coping strategies in pregnant, parturient and lactating rats. Progress in Brain Research, 133, 143-152. http://dx.doi.org/10.1016/S0079-6123(01)33011-X.

Neumann, I. D., Torner, L., \& Wigger, A. (2000). Brain oxytocin: differential inhibition of neuroendocrine stress responses and anxiety-related behaviour in virgin, pregnant and lactating rats. Neuroscience, 95, 567-575. http://dx.doi.org/10.1016/S0306-4522(99)00433-9.

Ohl, F., Roedel, A., Binder, E., \& Holsboer, F. (2003). Impact of high and low anxiety on cognitive performance in a modified hole board test in C57BL/6 and DBA/2 mice. European 
Journal of Neuroscience, 17, 128-136. http://dx.doi.org/10.1046/j.1460-9568.2003.02436.x.

Parker, G. A. (1974). Assessment strategy and the evolution of fighting behaviour. Journal of Theoretical Biology, 47, 223-243. http://dx.doi.org/10.1016/0022-5193(74)90111-8.

Pawluski, J. L., \& Galea, L. A. M. (2007). Reproductive experience alters hippocampal neurogenesis during the postpartum period in the dam. Neuroscience, 149, 53-67. http://dx.doi.org/10.1016/j.neuroscience.2007.07.031.

Pawluski, J. L., Walker, S. K., \& Galea, L. A. M. (2006). Reproductive experience differentially affects spatial reference and working memory performance in the mother. Hormones and Behavior, 49, 143-149. http://dx.doi.org/10.1016/j.yhbeh.2005.05.016.

Post, A. M., Weyers, P., Holzer, P., Painsipp, E., Pauli, P., Wultsch, T., Reif, A., \& Lesch, K-P. (2011). Gene-environment interaction influences anxiety-like behavior in ethologically based mouse models. Behavioural Brain Research, 218, 99-105. http://dx.doi.org/10.1016/j.bbr.2010.11.031.

Pozzo-Miller, L. D., Inoue, T., \& Murphy, D. D. (1999). Estradiol increases spine density and NMDA-dependent $\mathrm{Ca}^{2+}$ transients in spines of CA1 pyramidal neurons from hippocampal slices. Journal of Neurophysiology, 81, 1404-1411. http://jn.physiology.org/content/81/3/1404.short.

Prior, H., Schwegler, H., Marashi, V., \& Sachser, N. (2004). Exploration, emotionality, and hippocampal mossy fibers in nonaggressive $\mathrm{AB} / \mathrm{Gat}$ and congenic highly aggressive mice. Hippocampus, 14, 135-140. http://dx.doi.org/10.1002/hipo.10166.

Reeb-Sutherland, B. C., \& Tang, A. C. (2011). Dissociation between neonatal novelty-induced preferential maternal care and enhancement in cognitive, social, and emotional functions. Behavioural Brain Research, 224, 318-325. http://dx.doi.org/10.1016/j.bbr.2011.06.010. 
Rissanen, A., Puoliväli, J., van Groen, T., \& Riekkinen, P. Jnr. (1999). In mice tonic estrogen replacement therapy improves non-spatial and spatial memory in a water maze task.

NeuroReport, 10, 1369-1372.

http://journals.lww.com/neuroreport/Abstract/1999/04260/In_mice_tonic_estrogen_replaceme nt therapy.39.aspx.

Ross, H. E., \& Young, L. J. (2009). Oxytocin and the neural mechanisms regulating social cognition and affiliative behavior. Frontiers in Neuroendocrinology, 30, 534-547. http://dx.doi.org/10.1016/j.yfrne.2009.05.004.

Ruscio, M. G., Sweeny, T. D., Hazelton, J. L., Suppatkul, P., Boothe, E., \& Carter, C. S. (2008). Pup exposure elicits hippocampal cell proliferation in the prairie vole. Behavioural Brain Research, 187, 9-16. http://dx.doi.org/10.1016/j.bbr.2007.08.028.

Rymer, T. L., \& Pillay, N. (2011). The influence of the early rearing environment on the development of paternal care in African striped mice. Ethology, 117, 284-293. http://dx.doi.org/10.1111/j.1439-0310.2011.01873.x.

Rymer, T. L., \& Pillay, N. (2014) Alloparental care in the African striped mouse Rhabdomys pumilio is age-dependent and influences the development of paternal care. Ethology, 120, 1120. http://dx.doi.org/10.1111/eth.12175.

Salo, A. L, \& French, J. A. (1989). Early experience, reproductive success, and development of parental behaviour in Mongolian gerbils. Animal Behaviour, 38, 693-702. http://dx.doi.org/10.1016/S0003-3472(89)80015-6.

Saltzman, W., Thinda, S., Higgins, A. L., Matsumoto, W. R., Ahmed, S., McGeehan, L., \& Kolb, E. M. (2009). Effects of siblings on reproductive maturation and infanticidal behavior in cooperatively breeding Mongolian gerbils. Developmental Psychobiology, 51, 60-72. 
http://dx.doi.org/10.1002/dev.20347.

Schradin, C. (2004). Territorial defense in a group-living solitary forager: who, where, against whom? Behavioral Ecology and Sociobiology, 55, 439-446.

http://dx.doi.org/10.1007/s00265-003-0733-x.

Schradin, C., \& Pillay, N. (2004). The striped mouse (Rhabdomys pumilio) from the succulent karoo, South Africa: A territorial group-living solitary forager with communal breeding and helpers at the nest. Journal of Comparative Psychology, 118, 37-47. http://dx.doi.org/10.1037/0735-7036.118.1.37.

Schradin, C., \& Pillay, N. (2006). Female striped mice (Rhabdomys pumilio) change their home ranges in response to seasonal variation in food availability. Behavioral Ecology, 17, 452458. http://dx.doi.org/10.1093/beheco/arj047.

Schradin, C., \& Pillay, N. (2014). Absence of reproductive suppression in young adult female striped mice living in their natal family. Animal Behaviour 90, 141-148. http://dx.doi.org/10.1016/j.anbehav.2014.01.029.

Schradin, C., Schubert, M., \& Pillay, N. (2006). Winter huddling groups in the striped mouse. Canadian Journal of Zoology, 84, 693-698. http://dx.doi.org/10.1139/Z06-048.

Segal, M., \& Murphy, D. (2001). Estradiol induces formation of dendritic spines in hippocampal neurons: functional correlates. Hormones and Behavior, 40, 156-159. http://dx.doi.org/10.1006/hbeh.2001.1688.

Skinner, J. D., \& Chimimba, C. T. (2005). The mammals of the southern African subregion. Cape Town, South Africa: Cambridge University Press.

Tang, A. C., Akers, K. G., Reeb, B. C., Romeo, R. D., \& McEwen, B. S. (2006). Programming social, cognitive, and neuroendocrine development by early exposure to novelty. Proceedings 
of the National Academy of Science USA, 103, 15716-15721.

http://dx.doi.org/10.1073/pnas.0607374103.

Taylor, S. E., Klein, L. C., Lewis, B. P., Gruenewald, T. L., Gurung, R. A. R., \& Updegraff, J. A. (2000). Biobehavioral responses to stress in females: tend-and-befriend, not fight-or-flight. Psychological Review, 107, 411-429. http://dx.doi.org/10.1037/0033-295X.107.3.411.

Tomizawa, K., Iga, N., Lu, Y-F., Moriwaki, A., Matsushita, M., Li, S-T., Miyamoto, O., Itano, T., \& Matsui, H. (2003). Oxytocin improves long-lasting spatial memory during motherhood through MAP kinase cascade. Nature Neuroscience, 6, 384-390. http://dx.doi.org/10.1038/nn1023.

Toth, A. L., Varala, K., Newman, T. C., Miguez, F. E., Hutchison, S. K., Willoughby, D. A., Simons, J. F., Egholm, M., Hunt, J. H., Hudson, M. E. \& Robinson, G. E. (2007). Wasp gene expression supports an evolutionary link between maternal behavior and eusociality. Science, 318, 441-444. http://dx.doi.org/10.1126/science.1146647.

van der Kooij, M. A., Ohl, F., Arndt, S. S., Kavelaars, A., van Bel, F., \& Heijnen, C. J. (2010). Mild neonatal hypoxia-ischemia induces long-term motor- and cognitive impairments in mice. Brain, Behavior, and Immunity, 24, 850-856. http://dx.doi.org/10.1016/j.bbi.2009.09.003. van der Staay, F. J., Gieling, E. T., Pinzón, N. E., Nordquist, R. E., \& Ohl, F. (2012). The appetitively motivated "cognitive" holeboard: a family of complex spatial discrimination tasks for assessing learning and memory. Neuroscience and Biobehavioral Reviews, 36, 379403. http://dx.doi.org/10.1016/j.neubiorev.2011.07.008.

Wartella, J., Amory, E., Macbeth, A. H., McNamara, I., Stevens, L., Lambert, K. G., \& Kinsley, K. G. (2003). Single or multiple reproductive experiences attenuate neurobehavioral stress and fear responses in the female rat. Physiology \& Behavior, 79, 373-381. 
http://dx.doi.org/10.1016/S0031-9384(03)00150-1.

Watanabe, Y., Gould, E., \& McEwen, B. S. (1992). Stress induces atrophy of apical dendrites of hippocampal CA3 pyramidal neurons. Brain Research, 588, 341-345. http://dx.doi.org/10.1016/0006-8993(92)91597-8.

Wiedenmann, B., \& Franke, W. W. (1985). Identification and localization of synaptophysin, an integral membrane glycoprotein of Mr 38,000 characteristic of presynaptic vesicles. Cell, 41, 1017-1028. http://dx.doi.org/10.1016/S0092-8674(85)80082-9.

Windle, R. J., Wood, S., Shanks, N., Perks, P., Conde, G. L., da Costa, A. P. C., Ingram, C. D., \& Lightman, S. L. (1997). Endocrine and behavioural responses to noise stress: comparison of virgin and lactating female rats during non-disrupted maternal activity. Journal of Neuroendocrinology, 9, 407-414. http://dx.doi.org/10.1046/j.1365-2826.1997.00587.x.

Woodroffe, R., \& Vincent, A. (1994). Mothers' little helpers: patterns of male care in mammals. Trends in Ecology \& Evolution, 9, 294-297. http://dx.doi.org/10.1016/0169-5347(94)90033$\underline{7}$.

Woolley, C. S. (1998). Estrogen-mediated structural and functional synaptic plasticity in the female rat hippocampus. Hormones \& Behavior, 34, 140-148. http://dx.doi.org/10.1006/hbeh.1998.1466.

Woolley, C. S., \& McEwen, B. S. (1992). Estradiol mediates fluctuation in hippocampal synapse density during the estous cycle in the adult rat. Journal of Neuroscience, 12, 2549-2554. http://www.jneurosci.org/content/12/7/2549.short.

Woolley, C. S., \& McEwen, B. S. (1993). Roles of estradiol and progesterone in regulation of hippocampal dendritic spine density during the estrous cycle in the rat. Journal of Comparative Neurology, 336, 293-306. http://dx.doi.org/10.1002/cne.903360210. 
Ziegler, T. E., Washabaugh, K. F., \& Snowdon, C. T. (2004). Responsiveness of expectant male cotton-top tamarins Saguinus oedipus, to mate's pregnancy. Hormones \& Behavior, 45, 8492. http://dx.doi.org/10.1016/j.yhbeh.2003.09.003. 
Table 1. Mean ( \pm SE) squares crossed in four trials by female striped mice Rhabdomys pumilio in five treatments in the open field.

\begin{tabular}{lllll}
\hline Treatment & Trial 1 & Trial 3 & Trial 4 & Trial 6 \\
\hline Alloparent & $2.9(0.43)$ & $24.1(4.12)$ & $22.3(3.55)$ & $31.2(3.27)$ \\
Breeder & $2.8(0.51)$ & $23.0(3.81)$ & $16.7(2.34)$ & $27.4(4.98)$ \\
Barrier & $1.4(0.27)$ & $6.4(1.16)$ & $8.5(0.86)$ & $21.9(2.73)$ \\
Resident & $2.5(0.42)$ & $6.8(0.80)$ & $9.2(0.83)$ & $22.5(3.04)$ \\
Alone & $0.9(0.28)$ & $6.6(0.30)$ & $9.8(1.26)$ & $21.3(5.44)$ \\
\hline
\end{tabular}




\section{List of figures}

Fig. 1. Mean + SE disinhibition scores in two periods (trial 3-trial 1 and trial 6-trial 4) by striped mice Rhabdomys pumilio females in five treatments. Bars with the same letters are not significantly different (Fisher's HSD post hoc tests; $P<0.05$ ).

Fig. 2. Mean \pm SE number of seeds eaten (top panel) and duration (s) of exploratory behaviour (bottom panel) displayed by female striped mice Rhabdomys pumilio in five treatments on Day 1 of dyadic encounters. Bars with the same letters are not significantly different. Treatment did not predict the number of seeds consumed so no letters are provided.

Fig. 3. Mean \pm SE number of sunflower seeds consumed (top panel) and duration (s) of exploratory behaviour (bottom panel) displayed by female striped mice Rhabdomys pumilio in five treatments on Day 2 of dyadic encounters. Bars with the same letter are not significantly different. Treatment did not predict the number of seeds consumed so no letters are provided.

Fig. 4. Mean \pm SE latency (s) to resume feeding of sunflower seeds following a disturbance to female striped mice Rhabdomys pumilio in five treatments on Day 3 of dyadic encounters. Bars with the same letters are not significantly different.

Fig. 5. Mean \pm SE latency (s) to locate the baited hole in three maze configurations by female striped mice Rhabdomys pumilio in five treatments.

Fig. 6. Mean \pm SE time (s) spent in close proximity to the previously baited holes (duration; top panel) and the number of incorrect holes visited (errors; bottom panel) by female striped mice Rhabdomys pumilio in five treatments during a probe trial. Bars with the same letters are not significantly different. 


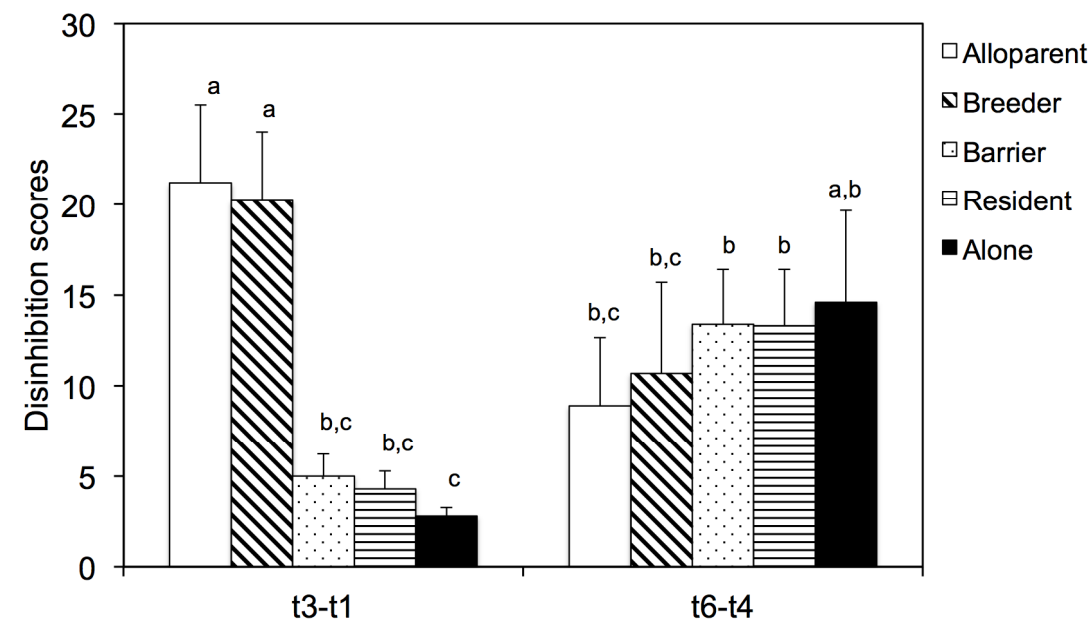

Fig. 1.

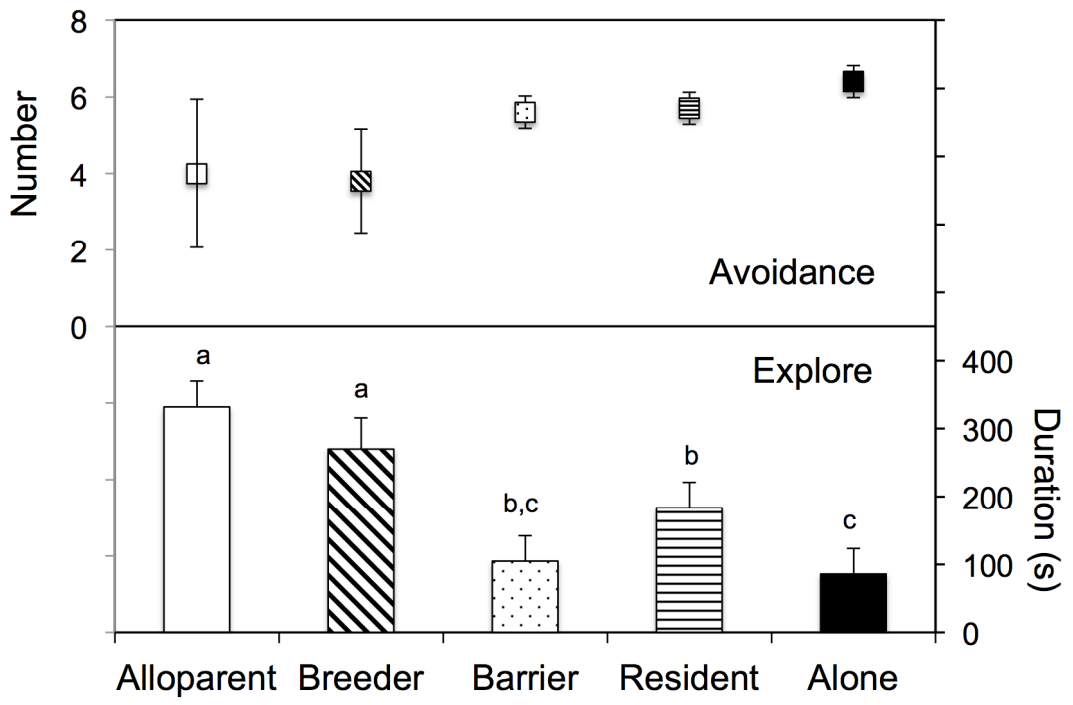

Fig. 2. 


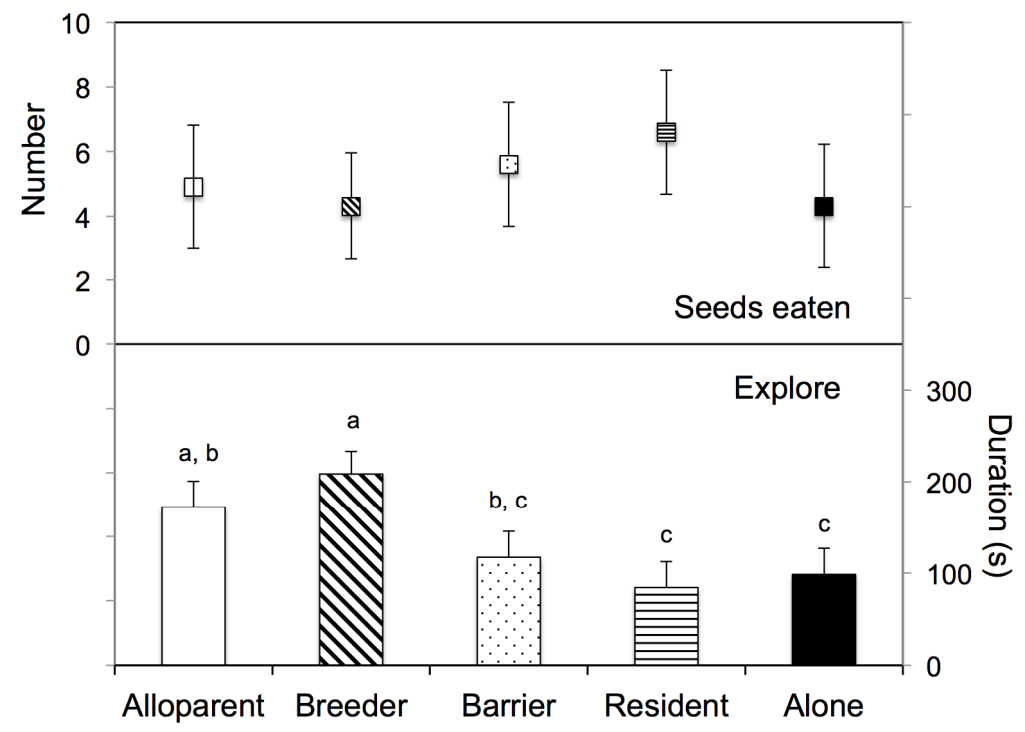

Fig. 3

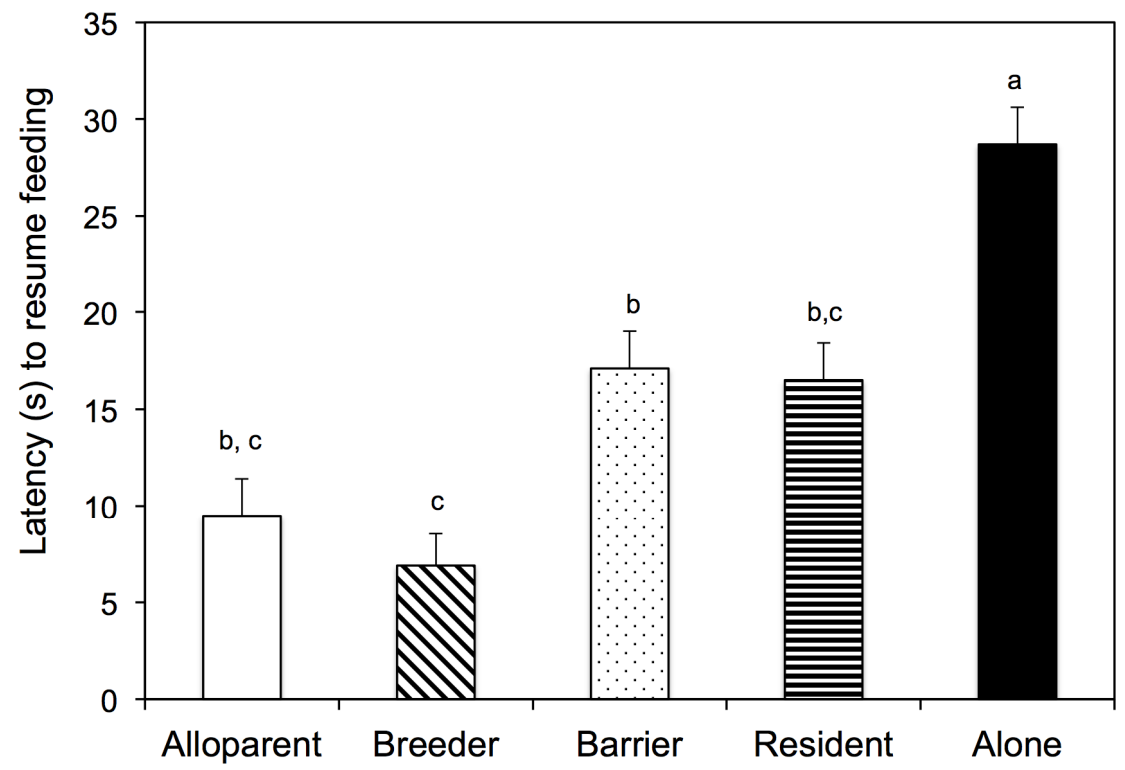

Fig. 4 


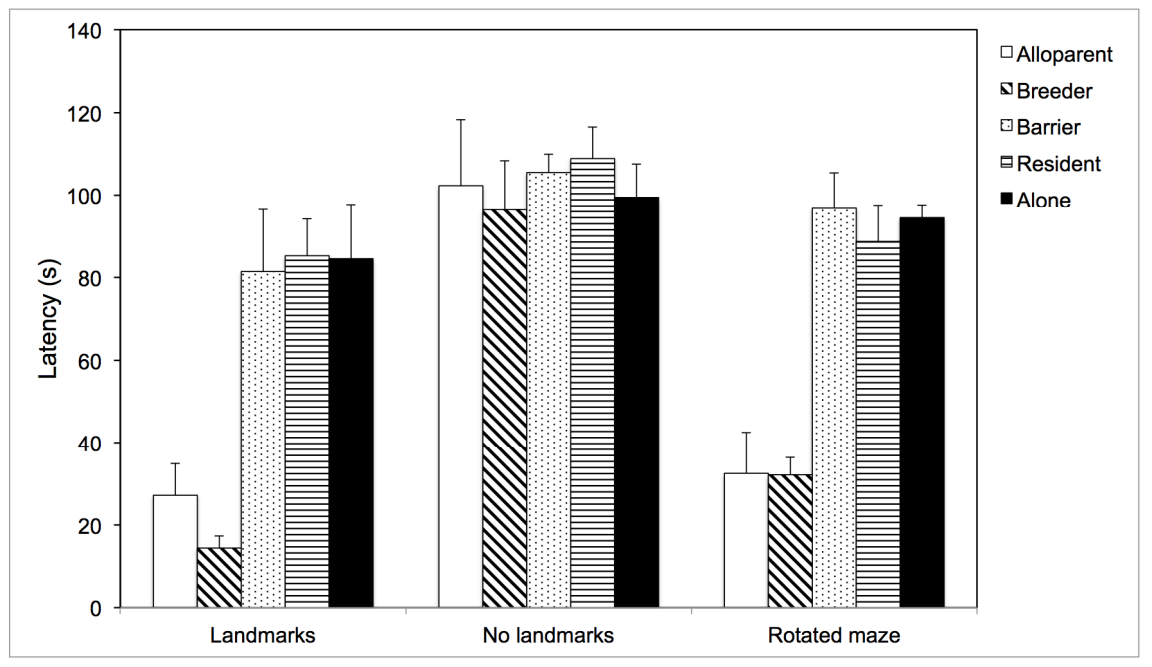

Fig. 5.



Fig. 6. 